04.1

\title{
Вольт-амперные характеристики начальной стадии дугового разряда в высоковольтном вакуумном диоде
}

\author{
() С.Г. Давыдов, А.Н. Долгов , А.В. Корнеев, Р.Х. Якубов \\ Всероссийский научно-исследовательский институт автоматики им. Н.Л. Духова, \\ Москва, Россия \\ ฯ E-mail: alnikdolgov@mail.ru
}

Поступило в Редакцию 22 марта 2019 г.

В окончательной редакции 22 марта 2019 г.

Принято к публикации 27 марта 2019 г.

В вакуумном диоде в облаке разреженной плазмы наблюдалось развитие электронной неустойчивости, а также прохождение катодного электронного пучка и пучка аномальных ионов с последующим всплеском тока на начальной стадии дугового разряда, что соответствует модели аномального ускорения ионов межэлектродной плазмы на искровой стадии вакуумного разряда.

Ключевые слова: искровой разряд, дуговой разряд, вакуумный диод, катодное пятно.

DOI: 10.21883/PJTF.2019.12.47916.17799

Сегодня управляемые малогабаритные вакуумные коммутаторы применяются в каротажной аппаратуре, высокоскоростной фотографии, устройствах подсветки быстропротекающих процессов импульсами оптического и рентгеновского излучения, а также в ряде других областей, где определяющими требованиями являются отсутствие накальных цепей, миниатюрность, широкий диапазон коммутируемых токов, устойчивость к внешним воздействиям [1]. Цель настоящей работы - изучить начальную стадию процесса коммутации в высоковольтном вакуумном диоде путем регистрации с временны́м разрешением наносекундного диапазона вольт-амперных характеристик основного дугового и вспомогательного искрового разрядов.

Разрядное устройство, использованное в экспериментах, представляет собой трехэлектродную осесимметричную систему. Диаметр цилиндрических соосных катода, поджигающего электрода и диэлектрической шайбы, разделяющей катод и поджигающий электрод, составляет $5 \mathrm{~mm}$. Электроды были выполнены из алюминиевого сплава, диэлектрическая шайба - из слюды. Коаксиальный анод в виде полого цилиндра имеет внутренний диаметр $7 \mathrm{~mm}$. Толщина диэлектрической шайбы 0.1-1 mm. Между диэлектрической шайбой и прилегающими электродами соосно с ними размещались дополнительно металлические прокладки, каждая толщиной $0.1 \mathrm{~mm}$ : между диэлектрической шайбой и поджигающим электродом - коваровая, между диэлектрической шайбой и катодом - коваровая и титановая [2]. Разрядное устройство размещается в герметичной диэлектрической оболочке, откачанной до давления остаточного газа $10^{-2}-1$ Ра и снабженной вакуумно-плотными выводамитоководами, позволяющими подключать электроразрядное устройство к внешним цепям.

Вакуумный диод выступает в роли коммутатора с переменным сопротивлением для $R L C$-контура, период собственных колебаний которого составляет $6 \mu \mathrm{s}$. Катод диода заземлен, анод до начала коммутации находится под положительным потенциалом величиной до $3 \mathrm{kV}$. Процесс коммутации стартует при подаче на поджигающий электрод положительного относительно катода импульса напряжения с амплитудой до $4 \mathrm{kV}$ и скоростью нарастания $(1-2) \cdot 10^{9} \mathrm{~V} / \mathrm{s}$. Происходит пробой по поверхности диэлектрической шайбы, и плазма, образованная продуктами эрозии, создает проводящую среду в промежутке катод-анод. Регистрируемая амплитуда тока в промежутке катод-анод составляет до 100 А. Измерения напряжения в промежутке катод-поджигающий электрод и катод-анод осуществлялись с помощью низкоиндуктивных омических и емкостных делителей. Сила тока определялась исходя из напряжения на низкоиндуктивном сопротивлении, включенном в соответствующую цепь.

На переднем фронте импульса основного тока, возникающего в промежутке катод-анод в результате перехода межэлектродной среды в проводящее состояние, в течение первых 20-60 ns регистрируются всплески тока, отвечающие протеканию тока как в „правильном“", т. е. соответствующем приложенному к промежутку катод-анод электрическому полю, так и в „неправильном“ направлении. Если в начале импульса тока на осциллограмме регистрируется всплеск „неправильной“ полярности, то он возникает практически одновременно с началом протекания тока поджига (рис. 1, a). Всплеск на переднем фронте импульса тока, соответствующий протеканию тока в „правильном“ направлении, всегда отстает от начала протекания тока поджига примерно на $10 \mathrm{~ns}$ (рис. 1,b). Амплитуда всплеска „правильной“ полярности может кратно превысить амплитуду основного импульса тока (рис. 2).

Регистрация напряжения в промежутке катод-анод позволяет по существу проследить изменения состояния 

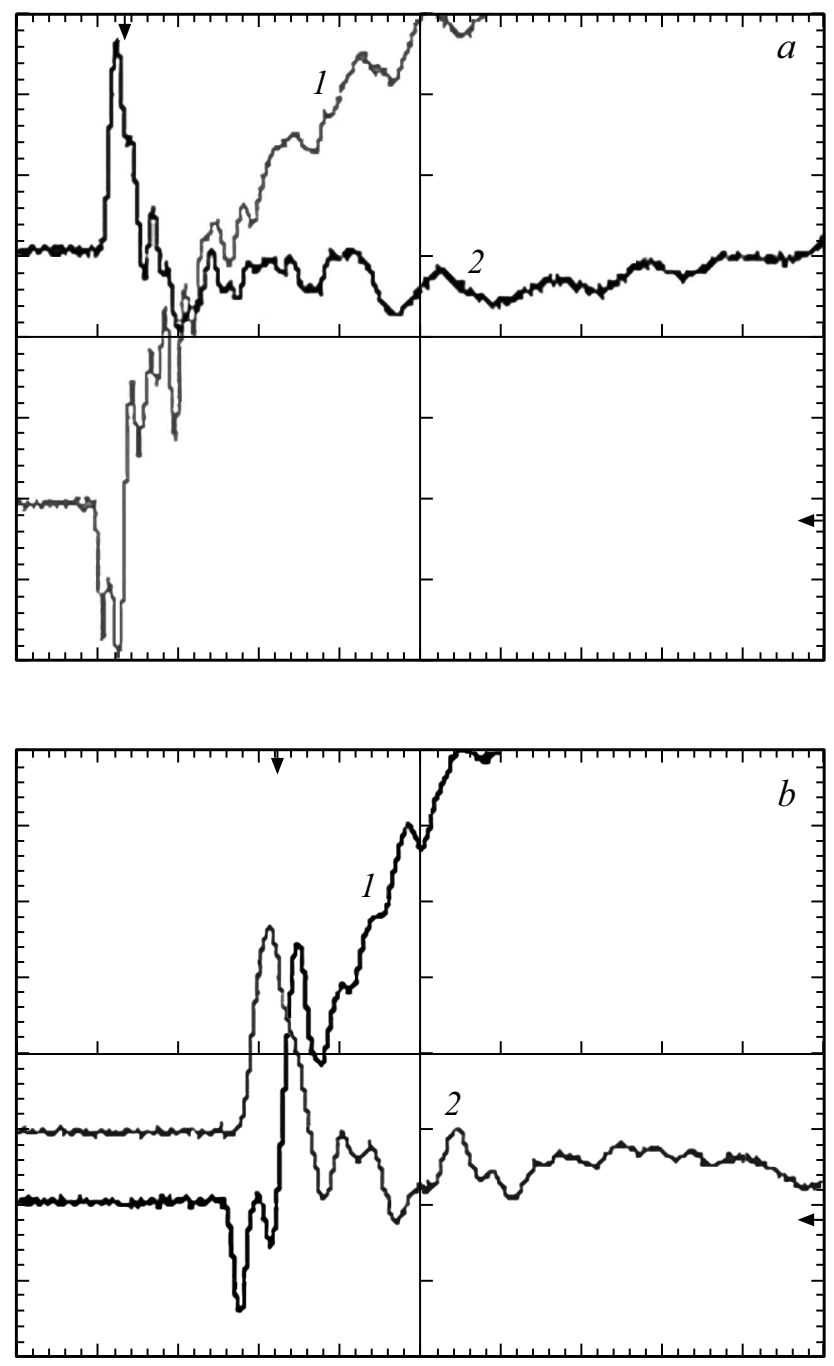

Рис. 1. Осциллограммы тока в промежутке катод-анод и тока поджига. Наблюдается всплеск на переднем фронте импульса тока в промежутке катод-анод, соответствующий протеканию тока в „неправильном“ $(a)$ и „правильном““ $(b)$ направлениях. Развертка $50(a)$ и $25 \mathrm{~ns} / \operatorname{div}(b)$. Луч 1 - ток в промежутке катод-анод, чувствительность $20 \mathrm{~A} / \mathrm{div}$, луч 2 - ток поджига, чувствительность $2 \mathrm{~A} / \mathrm{div}$.

проводимости среды в межэлектродном пространстве. Старт спада напряжения, свидетельствующий о начале процесса перехода среды из непроводящего в проводящее состояние, совпадает со стартом регистрируемого в диапазоне свыше 1 А тока поджига. Сила тока во вспомогательном разряде по поверхности диэлектрика позволяет считать, что мы имеем дело с искровым разрядом, а следовательно, мы наблюдаем процесс рождения и действия центров взрывной электронной эмиссии. Таким образом, процесс перехода среды из непроводящего в проводящее состояние происходит синхронно с процессом рождения и действия центров взрывной электронной эмиссии, по крайней мере с точностью до нескольких наносекунд.
На рис. 3 представлены измеренные синхронно осциллограммы тока и напряжения основного разряда в начальной его стадии. На переднем фронте импульса тока наблюдается пик тока в „правильном“ направлении, затем следует небольшой пичок „неправильной“ полярности и далее менее акцентированный всплеск тока в „правильном“ направлении с последующим относительно медленным возрастанием силы тока в разряде. Следует отметить, что в течение первых примерно 250 ns после старта регистрируемого тока, т.е. на стадии первых двух из указанных пиков („правильной“ и „неправильной“ полярности), происходят сильные колебания напряжения на межэлектродном промежутке.

В центрах взрывной электронной эмиссии, образующих катодное пятно в процессе поджигающего разряда по поверхности диэлектрика, достигается плотность потока энергии на поверхности катода порядка $10^{9} \mathrm{~J} / \mathrm{cm}^{2}$ [3], и они, точнее, испускаемые ими плазменные факелы должны являться яркими источниками ультрафиолетового излучения [4,5]. Ультрафиолетовое излучение в свою очередь способно эффективно и практически без временно́й задержки выбивать фотоэлектроны с поверхности в нашем случае анода. В пространстве между анодом и поджигающим электродом в момент пробоя по поверхности диэлектрика имеется область, в которой электрическое поле не только не препятствует, а напротив, способствует эмиссии фотоэлектронов с поверхности анода, что приводит к перераспределению потенциала электрического поля в межэлектродном пространстве и индуцированию на поверхности катода положительного заряда. В результате фиксируется ток „неправильного“ направления или пик „неправильнойс полярности на осциллограмме.

Ультрафиолетовое излучение, источником которого является плазма, образующаяся в центрах взрывной электронной эмиссии на стадии поджигающего разряда, должно ионизовать остаточный газ в объеме диода. Энергию этого излучения исходя из оценки энергии, выделяющейся в разряде по поверхности диэлектрика, с использованием осциллограмм напряжения и тока поджига можно принять равной $\sim 10^{-4} \mathrm{~J}$. При энергии квантов $\sim 10 \mathrm{eV}$ получаем количество испускаемых в поджиге квантов на уровне $N \sim 10^{14}$. Сечение фотоионизации молекул азота и кислорода, составляющих подавляющую часть остаточного газа, $\sigma_{f} \approx 10^{-17} \mathrm{~cm}^{2}[6]$. Сильное ионизирующее воздействие с вероятностью, близкой к единице, следует ожидать при плотности потока фотонов [7]:

$$
N_{f} \sim 1 / \sigma_{f} \sim 10^{17} \mathrm{~cm}^{-2} .
$$

Имеющуюся плотность потока фотонов оценим как

$$
N /\left(2 \pi \Delta R^{2}\right) \sim 10^{15} \mathrm{~cm}^{-2},
$$

где $\Delta R=1 \mathrm{~mm}$ - расстояние между катодом и анодом. Таким образом, можно ожидать примерно однопроцентной степени ионизации остаточного газа в промежутке 


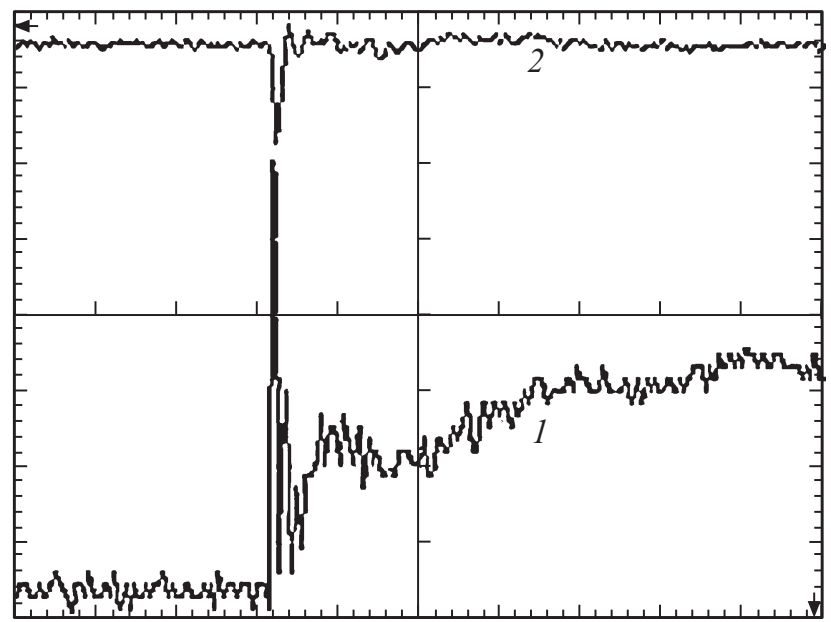

Pис. 2. Осциллограммы тока в промежутке катод-анод и тока поджига. Амплитуда всплеска „правильной“ полярности на переднем фронте импульса тока в промежутке катод-анод превышает амплитуду основного импульса тока примерно вдвое. Развертка $250 \mathrm{~ns} / \mathrm{div}$. Луч 1 - ток в промежутке катод-анод, чувствительность $10 \mathrm{~A} / \mathrm{div}$, луч 2 - ток поджига, чувствительность $5 \mathrm{~A} / \mathrm{div}$.

катод-анод под действием излучения катодного пятна на стадии развития поджигающего разряда. В пользу именно этого механизма формирования проводящей среды в промежутке катод-анод на начальной стадии развития основного разряда в вакуумном диоде свидетельствует задержка длительностью $\sim 10 \mathrm{~ns}$ процесса формирования разряда в промежутке катод-анод относительно тока поджига [8].

Скорость токового дрейфа электронов при концентрации носителей заряда $n \approx 10^{18} \mathrm{~m}^{-3}$, т.е. с учетом степени ионизации при давлении остаточного газа на уровне $1 \mathrm{~Pa}$, может составить уже при токе $1 \mathrm{~A}$ порядка

$$
V_{e} \approx I /(2 \pi R \Delta R e n) \approx 3 \cdot 10^{5} \mathrm{~m} / \mathrm{s}
$$

(где $R=2.5 \mathrm{~mm}$ - радиус катода), что явно будет превышать среднюю тепловую скорость ионов, а следовательно, и ионно-звуковую скорость в плазме. То, что данная проводящая среда является плазмой, доказывает соответствующая оценка радиуса Дебая

$$
r_{\mathrm{D}} \approx\left(\varepsilon_{0} k T /\left(e^{2} n\right)\right)^{1 / 2} \approx 10^{-4} \mathrm{~m}=0.1 \mathrm{~mm} \ll \Delta R,
$$

где $\varepsilon_{0}-$ диэлектрическая постоянная, $k-$ постоянная Больцмана, $T$ - электронная температура, $e-$ заряд электрона. Тепловая скорость ионов при температуре $5 \mathrm{eV}$, равной максимальной температуре, регистрируемой для электронов, составит $V_{i} \approx 4 \cdot 10^{3} \mathrm{~m} / \mathrm{s} \ll V_{e}$. Следствием данного обстоятельства станут раскачка колебаний электронной компоненты в плазме, аномальный рост сопротивления проводящей среды, формирование пучков убегающих электронов и амбиполярная диффузия плазмы в промежутке катод-анод [9]. Достаточно большая индуктивность разрядного контура приводит к тому, что значительные колебания разрядного тока могут отсутствовать, но при этом происходят довольно сильные колебания напряжения в промежутке катод-анод, вызванные колебаниями сопротивления плазмы разряда. Эти процессы прекращаются после замыкания межэлектродного промежутка плотной плазмой, инжектируемой из катодного пятна. Скорость распространения плазмы в результате амбиполярной диффузии составляет $\sim 10^{4} \mathrm{~m} / \mathrm{s}[10]$; следовательно, время, необходимое для создания хорошо проводящей среды и перехода к дуговой стадии, составит $\sim 10^{-7} \mathrm{~s}$.

Авторы [11] методами математического моделирования показали, что ускорение ионов на искровой стадии вакуумного разряда может происходить при наличии в межэлектродном промежутке плазменного облака. Развитие в этой плазме сильной электронной неустойчивости при прохождении катодного электронного пучка приведет к росту ее потенциала до значений, превышающих приложенную разность потенциалов. Следует ожидать, что появление аномально ускоренных ионов в межэлектродной плазме будет сопровождаться всплеском тока в диоде.

Наши данные подтверждают результаты моделирования: мы наблюдаем признаки образования в межэлектродном промежутке плазменного облака в результате фотоионизации остаточного газа; регистрируем развитие сильной электронной неустойчивости; наблюдаем прохождение электронного пучка, распространяющегося от катода к аноду (пик „правильной“ полярности), и распространение пучка ионов в том же направлении (пичок „неправильной“ полярности); фиксируем на переднем фронте импульса тока всплески, амплитуда которых по крайней мере в 2 раза превышает амплитуду основной части импульса.

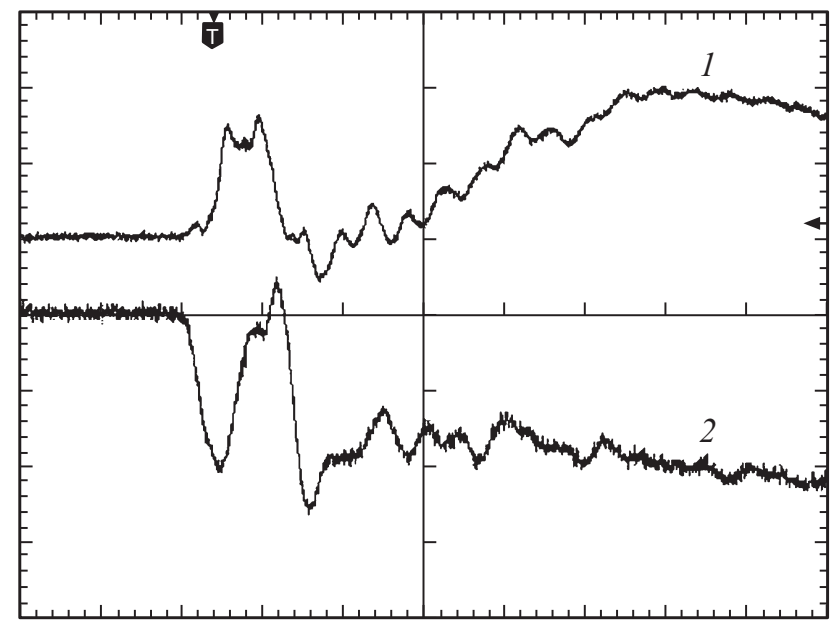

Рис. 3. Осциллограммы тока и напряжения на начальной стадии разряда в промежутке катод-анод. Развертка $40 \mathrm{~ns} / \mathrm{div}$. Луч 1 - ток в промежутке катод-анод, чувствительность $20 \mathrm{~A} / \mathrm{div}$, луч 2 - напряжение в промежутке катод-анод, чувствительность $2 \mathrm{kV} / \mathrm{div}$. 


\section{Конфликт интересов}

Авторы заявляют, что у них нет конфликта интересов.

\section{Список литературы}

[1] Месяч Г.А. Импульсная энергетика и электроника. М.: Наука, 2004. $704 \mathrm{c}$

[2] Асюнин В.И., Давыдов С.Г., Долгов А.Н., Козловская Т.И., Пшеничный А.А., Якубов P.X. // Вопр. атомной науки и техники. Сер. Термоядерный синтез. 2015. Т. 38. В. 3. C. $49-52$.

[3] Mesyats G.A., Bochkarev M.B., Petrov A.A., Barengolts S.A. // Appl. Phys. Lett. 2014. V. 104. N 18. P. 184101.

[4] Воробьев В.С. // УФН. 1993. Т. 123. № 12. С. 51-83.

[5] Ананьин О.Б., АЯанасьев Ю.В., Крохин О.Н. Лазерная плазма: физика и применение. М.: МИФИ, 2003. 400 с.

[6] Бабичев А.П., Бабушкина Н.А., Братковский А.М. Физические величины. М.: Энергоатомиздат, 1991. 1232 с.

[7] Арифов Т.У., Аскарьян Г.А., Тарасова Н.М. // Письма в ЖЭТФ. 1968. Т. 8. В. 3. С. $128-132$.

[8] Аскарьян Г.А., Королев М.Г., Корчагина Е.Г., Якушкин К.Л. // Письма в ЖЭТФ. 1994. Т. 60. В. 1. С. 11-15.

[9] Михайловский А.Б. Теория плазменных неустойчивостей. T. 1. Неустойчивости однородной плазмы. М.: Атомиздат, 1975. $272 \mathrm{c}$

[10] Месяи, Г.А. Эктоны в вакуумном разряде: пробой, искра, дуга. М.: Наука, 2000. 424 с.

[11] Шмелев Д.Л., Месяи, Г.А., Баренгольи, С.А. // Письма в ЖТФ. 2007. Т. 33. В. 10. С. 19-26. 